\title{
Does Offline Beat Inline Treatment: Investigation into Extracorporeal Photopheresis
}

\author{
Wolfgang Helmberg ${ }^{a}$ Sabine Sipurzynski ${ }^{a} \quad$ Andrea Groselje-Strehle ${ }^{b}$ \\ Hildegard Greinix ${ }^{c}$ Peter Schlenke ${ }^{a}$ \\ a Blood Group Serology and Transfusion Medicine, Medical University Graz, Graz, Austria; \\ ${ }^{b}$ Core Facility Computational Bioanalytics, Center for Medical Research, Medical University Graz, Graz, Austria; \\ 'Division of Hematology, Medical University Graz, Graz, Austria
}

\section{Keywords}

Extracorporeal photopheresis · Inline treatment · Offline treatment · Photopheresis · Quality control

\begin{abstract}
Background: Extracorporeal photopheresis is a therapy based on the induction of apoptosis to cells harvested from peripheral blood, followed by direct retransfusion. Currently, there are two approaches: inline procedures, where cell harvesting, 8-methoxypsoralen (8-MOP) incubation, and UV irradiation is performed with a single device, and offline procedures, with collection in one device, followed by 8-MOP incubation/UV irradiation using a second device. Study Design and Methods: In a prospective crossover study, we compared an inline (Cellex, Therakos) with an established offline procedure (Optia, Terumo, and MacoGenic G2, Macopharma) in 6 patients, focusing on cell composition and apoptosis induction after $24 \mathrm{~h}$. In total, 32 photopheresis treatments per device were performed. Results: We observed an overall 2-fold higher number of apoptotic "target" cells for each patient with offline treatment. All yields were stratified per patient. Yields were compared as ratio offline/ inline for CD3+ (2.5-fold), CD4+ (2-fold), CD8+ (2.8-fold), CD56+ (2.8-fold), CD19+ (1.8-fold), CD15+ (0.5-fold), and CD14+ (2.2-fold) cells. Apoptosis induction was measured after $24 \mathrm{~h}$ with Annexin V/7-AAD for early and late apoptosis rates of $\mathrm{CD} 3+(\mathrm{CD} 4+, \mathrm{CD} 8+)$ and $\mathrm{CD} 56+$ cells. CD3+ cells of the inline treatment had an average of $88 \%$ (26\% early, $62 \%$
\end{abstract}

late) of apoptotic cells compared to $75 \%$ (34\% early, $41 \%$ late) in the offline treatment. Procedure duration ranged from 80 to 100 min inline, with a maximum of 1,500 mL processed blood, and 125-140 min offline, with at least 3,000 $\mathrm{mL}$ processed blood, depending on blood flow. Average hematocrit levels of the products were $2.7 \%$ inline versus $1.7 \%$ offline. Conclusions: The offline procedure, as established in our department, provides more apoptotic cells for treatment. The increased number of mononuclear cells collected outweighs a slightly reduced apoptosis rate after $24 \mathrm{~h}$ in comparison to the inline procedure. Besides this, the final decision for one or the other procedure has to take into account additional aspects, such as peripheral white blood cell count, hematocrit, and weight of the patient, required before apheresis, extracorporeal volume, and, last but not least, overall costs. The final criterion, however, has to be the reported clinical efficacy of the system applied.

๑) 2020 S. Karger AG, Basel

\section{Introduction}

Extracorporeal photopheresis (ECP) is an immunemodulating therapy based on the induction of apoptosis of cells harvested from peripheral blood (PB) via apheresis. This therapy has been established for several diseases, such as cutaneous T-cell lymphoma, as a second-line therapy of graft-versus-host disease (GvHD), organ transplant rejection, and autoimmune-like diseases [1- 
6]. Especially ECP treatment of acute and chronic GvHD has been a subject of intense investigation [7-12]. Guidelines recommend ECP as second-line therapy of both acute and chronic steroid-refractory GvHD [13].

ECP requires an apheresis procedure where collected cells are incubated with 8-methoxypsoralen (8-MOP), subsequently irradiated with UV light, and then retransfused. The 8-MOP treatment is postulated to cause an intercalation of 8-MOP with DNA strands, with a subsequent induction of apoptosis of all treated cells [14-16].

For this therapy, either an inline or an offline procedure can be chosen [17]. The inline procedure is performed with a device that includes both the apheresis and irradiation unit, while the offline procedure collects cells in one device and irradiates them in a second device. This study focused on cellular yield and apoptotic cell dose obtained from extended quality control of both ECP procedures. To the best of our knowledge, this is the first study to compare directly cell composition and number of apoptotic mononuclear cells (MNCs) between an inline and offline system.

\section{Material and Methods}

\section{Photopheresis Procedures}

For the inline procedure, Cellex (Therakos, Mallinckrodt, Dublin, Ireland) was used, for the offline procedure Optia (Terumo BCT, Tokyo, Japan) with the UV irradiation device MacoGenic G2 (Macopharma, Tourcoing, France), with a protocol already established in our department. Six patients were treated in a crossover design, both inline and offline, with an expected number of 6 photopheresis procedures on each system. Cell analysis was part of the extended quality control of photopheresis products, utilizing the routinely drawn quality control samples.

Six patients were included: 1 with Sezary syndrome and 5 with acute GvHD after hematopoietic stem cell transplantation for acute myeloid leukemia $(n=2)$, myelodysplastic syndrome $(n=2)$, and primary myelofibrosis $(n=1)$. Four were males, 2 were females, body weight ranged from 50 to $82 \mathrm{~kg}$, and hematocrit (HCT) from 25 to $38.2 \%$.

On Cellex, preset 1,500 $\mathrm{mL}$ of blood was processed to retrieve the buffy coat with a Latham bowl. The manufacturer's instructions require the patient's HCT to be at least $27 \%$ to start the procedure. The volume of the buffy coat is variable based on the WBC count and was diluted within the process with physiological saline solution. 8-MOP was added according to the manufacturer's protocol (product volume $\times 0.017$ ), usually totaling around $60 \mu \mathrm{g}$ 8 -MOP per treatment. Irradiation time was automatically set by the device depending on HCT $(20-40 \mathrm{~min})$ at $1.5 \mathrm{~J} / \mathrm{cm}^{2}$. Product volumes were recorded based on the device's display.

On Optia, the MNC continuous collection program was used to collect $120 \mathrm{~mL}$ product with a collection rate of $1 \mathrm{~mL} / \mathrm{min}$. The processed blood volume $(>3,000 \mathrm{~mL})$ depended on the blood flow. The collected product was transferred into an irradiation bag and diluted to $200 \mathrm{~mL}$ with a physiological saline solution. One $\mathrm{mL}$ of 8-MOP (Uvadex, Therakos)/100 mL product was applied according to the manufacturer's protocol of the irradiation device, totaling $40 \mu \mathrm{g} 8$-MOP per treatment. Irradiation time was set to $10 \mathrm{~min}$ with a dosage of $2 \mathrm{~J} / \mathrm{cm}^{2}$, based on an HCT $<2 \%$.
PB cell counting was obtained before each apheresis procedure, a quality control sample $(2 \mathrm{~mL})$ of the product was drawn before and after irradiation. Of each $2-\mathrm{mL}$ sample, $300 \mu \mathrm{L}$ were sterilely removed for cell counting. Initial cell composition was measured on FACS Navios (Beckman Coulter, Krefeld, Germany) based on a life gate for CD45-KrO in two tubes, one with CD56-PE, CD3-PB, CD8-AF 700, and CD4-APC, the other with CD14-APC, CD15-PB, and CD19-PE (all Beckman Coulter). Approximately $5 \times 10^{5}$ cells were incubated with a cocktail of $10 \mu \mathrm{L}$ of each antibody, except for $5 \mu \mathrm{L}$ CD4-APC, for $15 \mathrm{~min}$ and subsequently measured. To culture the treated and untreated samples, a sterile filtered culture medium was prepared with $9 \mathrm{~mL}$ Iscove basal medium (Biochrom $\mathrm{GmbH}$, Berlin, Germany), $1 \mathrm{~mL}$ AB Octaplas (Octapharma), $100 \mu \mathrm{L}$ penicillin/streptomycin, and $4 \mu \mathrm{L}$ heparin.

\section{Measurement of Apoptosis}

Apoptosis was measured for CD3 with the subsets CD4 and CD8 as well as CD56-positive cells. The samples were centrifuged with $433 \mathrm{~g} / 5 \mathrm{~min} / 4^{\circ} \mathrm{C}$. The supernatant was removed, cells were resuspended in $0.5 \mathrm{~mL}$ added to a flask with $4.5 \mathrm{~mL}$ culture medium and kept in the incubator at $37^{\circ} \mathrm{C}$. No Ficoll was used for separation in order to reduce any additional stress for the cells. Apoptosis was measured at start of culture and after $24 \mathrm{~h}$ for both treated and untreated cells. No red cell lysis was used. 5 to $10 \times 10^{6}$ cells were taken from culture into a tube prefilled with $4^{\circ} \mathrm{C}$ PBS and centrifuged ( $433 \mathrm{~g} / 5 \mathrm{~min}, 4^{\circ} \mathrm{C}$ ), supernatant was removed, and set to a concentration of $5 \times 10^{3} / \mu \mathrm{L}$ with ice-cold binding buffer of the Annexin A5 FITC/7-AAD kit (IMMUNOTECH S.A.S., Beckman Coulter). $100 \mu \mathrm{L}$ of cell suspension was then incubated with an apoptosis antibody cocktail. The antibody cocktail contained 10 $\mu \mathrm{L}$ CD45-KrO, $10 \mu \mathrm{L}$ CD56-PE, $10 \mu \mathrm{L}$ CD3-PacificBLue, $10 \mu \mathrm{L}$ CD8-AF 700, $5 \mu \mathrm{L}$ CD4-APC, $10 \mu \mathrm{L}$ Annexin V-FITC, and $20 \mu \mathrm{L}$ 7 -AAD, was gently mixed and incubated for $15 \mathrm{~min}$ on ice in the dark. After addition of $400 \mu \mathrm{L}$ ice-cold binding buffer, the cells were measured within $30 \mathrm{~min}$. Cells were life-gated on CD45 and then gated for CD3, CD4, CD8, CD56, and the gated populations plotted in quadrants for Annexin V-FITC and 7-AAD. Baselines of the quadrants were set based on the day 0 of the untreated cells and kept constant.

\section{Statistical Analysis}

A repeated-measurements linear mixed-effects model was performed as a restricted maximum likelihood (REML) approach. Two analyses with the percentage of CD3+ apoptosis and absolute $\mathrm{CD} 3+$ apoptotic number as the dependent variable in the model were performed. Separator (Cellex and Optia) and type (untreated or treated) were included as within-group effects. "Patient" was considered as a person-specific random effect. A Wilcoxon signedrank test was used to compare CD4+ and CD8+ apoptosis. A twotailed $p$ value of $<0.05$ was considered as statistically significant. All statistical tests were performed using SPSS version 25.0 (SPSS Inc., Chicago, IL, USA).

For descriptive analysis, cell yields of apheresis products were averaged for each patient in a first step in order to account for the patient-specific variation, resulting in a relative benchmark of the inline system as 1 . Then, the offline/inline ratio of the averaged patient yields was calculated and given as mean and a standard deviation. Apoptosis percentages were averaged over all samples of each patient. Relative number of apoptotic cells was determined by first calculating the total number of apoptotic cells based on the 24-h measurements and then averaging these amounts in a twostep approach, i.e., comparing the averages of each patient, corresponding to the previously described cell yield comparison, providing mean and standard deviation. 
Fig. 1. Relative yield of cells per patient $(n=6)$. The yield of each cell type has been stratified per patient; thus, the yield of the inline system (Cellex) is displayed with the value " 1 ." The variation represents the variation of the averaged values of each patient.

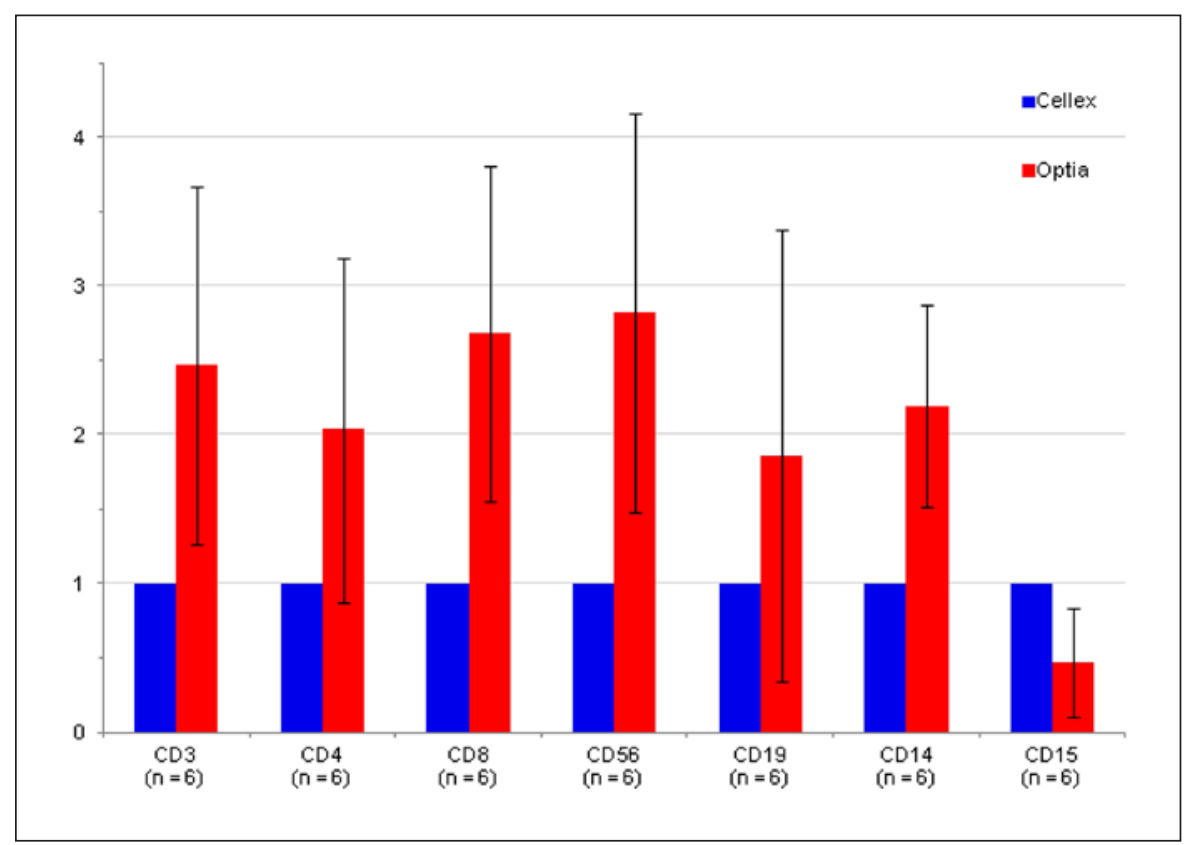

Table 1. Summary of collection data

\begin{tabular}{lcc}
\hline & Inline $(n=32)$ & Offline $(n=32)$ \\
\hline Blood volume processed, $\mathrm{mL}$ & $1,500 \pm 0$ & $5,911 \pm 711$ \\
Collection time, min & $102 \pm 22$ & $145 \pm 19+25$ irrad./transf. \\
Product volume, $\mathrm{mL}$ & $189 \pm 23$ & $212 \pm 10$ \\
Hematocrit, \% & $2.7 \pm 0.7$ & $1.7 \pm 0.5$ \\
Hemoglobin, g/dL & $0.6 \pm 0.1$ & $0.3 \pm 0.1$ \\
Range of MNCs collected/patient, $\times 10^{9}$ & $0.36 \pm 0.12$ to $2.25 \pm 0.71$ & $1.02 \pm 0.39$ to $7.65 \pm 2.19$
\end{tabular}

\section{Results}

Although the inline ECP system was consistently able to induce higher percentages of apoptotic MNCs, the overall apoptotic cell number was significantly (2-fold) higher in the offline system. Four patients were included with 6 ECP procedures using both the inline and offline ECP systems, one with 5 and one with 3 ECP treatments, totaling $32 \mathrm{ECP}$ procedures for each system. The peripheral WBC count had a range from 1.3 to $11.5 \times 10^{3} / \mu \mathrm{L}$, with the MNC in a range from 0.15 to $4.07 \times 10^{3} / \mu \mathrm{L}$. Apheresis data are summarized in Table 1. Apheresis duration ranged from 80 to 100 min using the inline system and from 125 to $140 \mathrm{~min}$ using the offline system. Average HCT of the product after addition of physiological saline solution was $2.7 \%$ inline versus $1.7 \%$ offline. The ratio of offline/inline yield resulted in values as shown in Figure 1: CD3+ (2.5-fold), CD4+ (2.0-fold), CD8+ (2.8fold $), \mathrm{CD} 56+(2.8$-fold $), \mathrm{CD} 19+(1.8$-fold $), \mathrm{CD} 15+(0.5-$ fold), and CD14+ (2.2-fold) cells. Apoptosis measurement on FACS differentiated between early and late apoptosis, early with Annexin V-positive/7-AAD-nega- tive events, late apoptosis represented by both Annexin $\mathrm{V}$ - and 7-AAD-positive events. Measurement required inclusion of a distinct smaller and more fragmented cell cluster, representing mainly late apoptotic cells (Fig. 2). Apoptosis after $24 \mathrm{~h}$ was determined for $\mathrm{CD} 3+, \mathrm{CD} 4+$, CD8+, and CD56+ cells (Table 2). Untreated CD3+ cells of the inline procedure had an average of 55\% (38\% early, $16 \%$ late) apoptotic cells and 48\% (37\% early, 11\% late) with offline treatment as shown in Table 2. Treated CD3+ cells had an average of $88 \%$ (26\% early, 62\% late) apoptotic cells in inline treatment and 75\% (34\% early, 41\% late) in offline treatment. REML analysis was applied on apoptotic CD3+ cells with inline outperforming offline with a $p<0.001$. CD4+ cells were significantly less susceptible to apoptosis (inline $84 \pm 11 \%$, offline $59 \pm 16 \%$ ) than CD8+ cells (inline $91 \pm 8 \%$, offline $82 \pm 10 \%$; Wilcoxon signed-rank test, $p<0.001)$.

The predicted number of apoptotic cells is shown in Figure 3 and Table 2, based on the apoptosis measurement of treated cells, without adjustments based on the values of untreated cells. The calculation resulted in an averaged 2-fold increased number of apoptotic MNCs for 


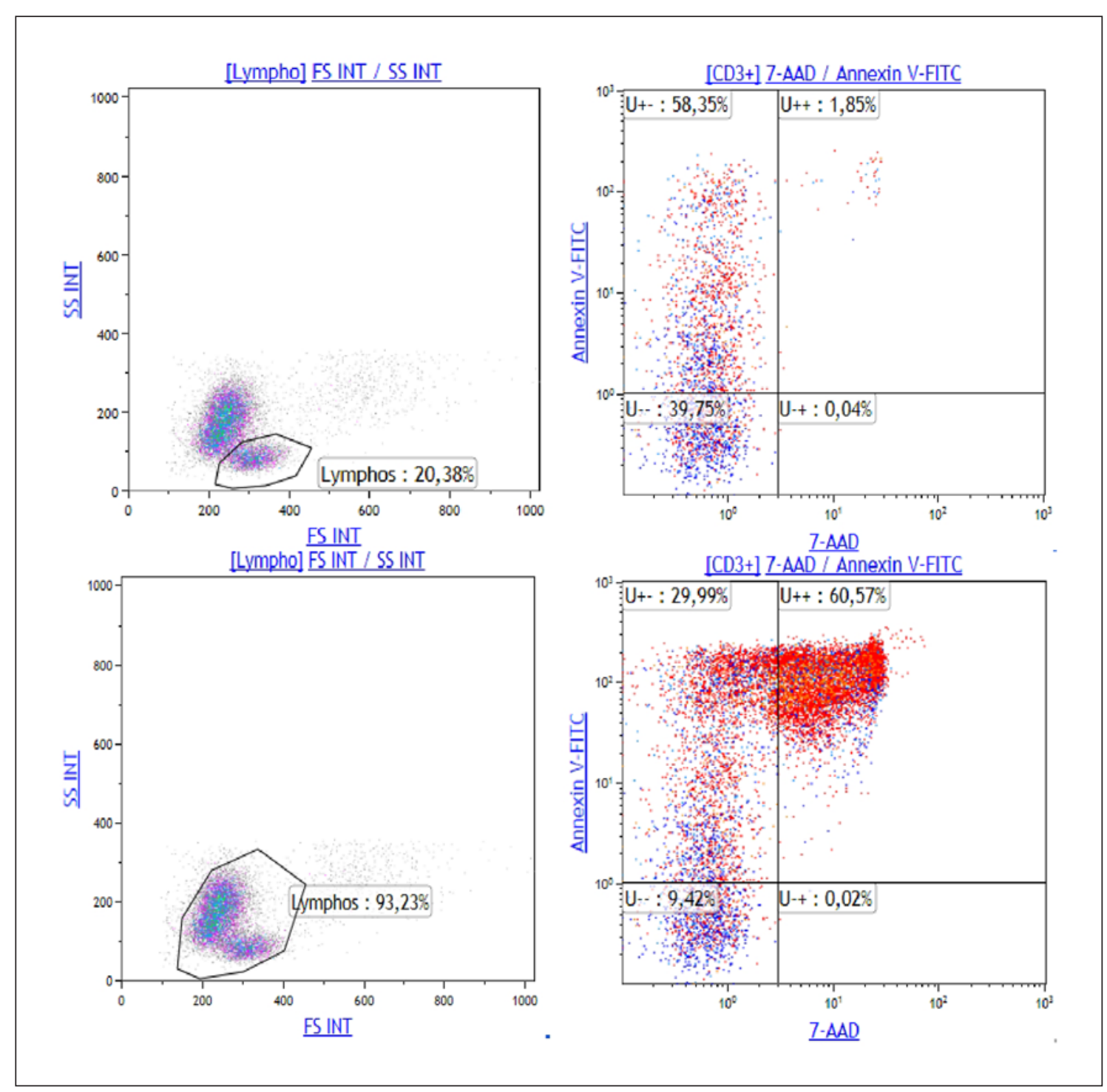

Fig. 2. After $24 \mathrm{~h}$, two distinct populations of cells can be identified in the forward scatter/side scatter plot. The smaller, less granulated events represent the late apoptotic cells and have to be included in the analysis.

the offline in comparison with the inline treatment. The difference in these numbers was significant (REML, $p<$ 0.001). An adjustment based on the observed apoptosis of untreated cells increased the dosage in favor of the offline treatment. The offline system required an additional time of $35 \mathrm{~min}$ for handling, incubation with 8-MOP, irradiation, and retransfusion, the treatment time totaling to almost $3 \mathrm{~h}$ in contrast to around $100 \mathrm{~min}$ for the inline procedure.

\section{Discussion}

A clinical department offering photopheresis treatment has to decide which system to use under various points of view: efficacy of the in vitro induced treatment and its clinical outcome, admission criteria for patients to undergo treatment, surveillance of the patient during treatment, user friendliness of the procedures, and, last but not least, the costs involved per treatment.

Although extracorporeal photopheresis treatment is widely used as a second-line treatment of GvHD, the exact "pharmaceutical" mechanism of this therapy remains unclear. There are no hard facts or data points that can be used to predict the clinical efficacy of an ECP apheresis product $[18,19]$, although there is some indication that distinct cell populations within the recipient might be a prerequisite for successful treatment [20]. A factor that can be measured as quality control of ECP therapy is the dose of apoptotic MNCs [21] or the number of lymphocytes and MNCs/kg body weight given per single procedure [22]. The main factor contributing to the number of 
Table 2. Apoptosis $(n=32)$ of cells immediately after culture and after $24 \mathrm{~h}$ and relative number of apoptotic cells

\begin{tabular}{|c|c|c|c|c|c|c|c|c|c|c|c|c|}
\hline & \multicolumn{3}{|c|}{ CD3+ apoptosis, \% } & \multicolumn{3}{|c|}{ CD4+ apoptosis, \% } & \multicolumn{3}{|c|}{ CD8+ apoptosis, \% } & \multicolumn{3}{|c|}{ CD56+ apoptosis, $\%$} \\
\hline & total & early & late & total & early & late & total & early & late & total & early & late \\
\hline \multicolumn{13}{|c|}{ Apoptosis at 1 h after cultivation $(n=32)$} \\
\hline \multicolumn{13}{|c|}{ Untreated } \\
\hline Inline & $27 \pm 24$ & $26 \pm 23$ & $1 \pm 1$ & $19 \pm 19$ & $17 \pm 18$ & $1 \pm 2$ & $33 \pm 28$ & $32 \pm 28$ & $1 \pm 1$ & $15 \pm 13$ & $14 \pm 13$ & $0 \pm 0$ \\
\hline Offline & $16 \pm 9$ & $16 \pm 9$ & $0 \pm 1$ & $10 \pm 5$ & $9 \pm 5$ & $1 \pm 1$ & $19 \pm 11$ & $19 \pm 11$ & $0 \pm 0$ & $7 \pm 3$ & $6 \pm 3$ & $0 \pm 0$ \\
\hline \multicolumn{13}{|l|}{$8 \mathrm{MOP} / \mathrm{UV}$} \\
\hline Inline & $32 \pm 24$ & $31 \pm 23$ & $1 \pm 1$ & $22 \pm 18$ & $21 \pm 17$ & $1 \pm 1$ & $38 \pm 28$ & $37 \pm 28$ & $1 \pm 1$ & $17 \pm 13$ & $16 \pm 13$ & $0 \pm 0$ \\
\hline Offline & $18 \pm 12$ & $18 \pm 12$ & $0 \pm 0$ & $11 \pm 7$ & $11 \pm 7$ & $0 \pm 1$ & $22 \pm 14$ & $21 \pm 14$ & $0 \pm 0$ & $9 \pm 6$ & $9 \pm 6$ & $0 \pm 0$ \\
\hline \multicolumn{13}{|c|}{ Apoptosis at $24 \mathrm{~h}$ after cultivation $(n=32)$} \\
\hline \multicolumn{13}{|c|}{ Untreated } \\
\hline Inline & $55 \pm 20$ & $38 \pm 13$ & $16 \pm 11$ & $41 \pm 15$ & $30 \pm 11$ & $11 \pm 7$ & $63 \pm 21$ & $44 \pm 13$ & $19 \pm 13$ & $39 \pm 21$ & $31 \pm 19$ & $8 \pm 7$ \\
\hline Offline & $48 \pm 17$ & $37 \pm 13$ & $11 \pm 8$ & $34 \pm 15$ & $26 \pm 12$ & $8 \pm 6$ & $57 \pm 16$ & $43 \pm 12$ & $13 \pm 9$ & $34 \pm 16$ & $29 \pm 16$ & $5 \pm 6$ \\
\hline \multicolumn{13}{|l|}{$8 \mathrm{MOP} / \mathrm{UV}$} \\
\hline Inline & $88 \pm 11$ & $26 \pm 9$ & $62 \pm 11$ & $84 \pm 11$ & $23 \pm 10$ & $61 \pm 12$ & $91 \pm 8$ & $29 \pm 8$ & $62 \pm 11$ & $81 \pm 15$ & $26 \pm 10$ & $55 \pm 15$ \\
\hline \multirow[t]{3}{*}{ Offline } & $75 \pm 12$ & $34 \pm 10$ & $41 \pm 13$ & $59 \pm 16$ & $29 \pm 10$ & $30 \pm 14$ & $82 \pm 10$ & $38 \pm 10$ & $44 \pm 14$ & $73 \pm 17$ & $29 \pm 11$ & $44 \pm 17$ \\
\hline & \multicolumn{3}{|c|}{$\mathrm{CD} 3+$ dosage } & \multicolumn{3}{|c|}{ CD4+ dosage } & \multicolumn{3}{|c|}{ CD8+ dosage } & \multicolumn{3}{|c|}{ CD56+ dosage } \\
\hline & total & early & late & total & early & late & total & early & late & total & early & late \\
\hline Offline/inline & $2.1 \pm 1.21$ & $2.9 \pm 0.76$ & $1.8 \pm 1.42$ & $1.5 \pm 0.93$ & $2.5 \pm 1.15$ & $1.2 \pm 0.97$ & $2.4 \pm 1.1$ & $3.3 \pm 0.83$ & $2.1 \pm 1.29$ & $2.6 \pm 1.46$ & $3.2 \pm 1.63$ & $2.3 \pm 1.33$ \\
\hline
\end{tabular}

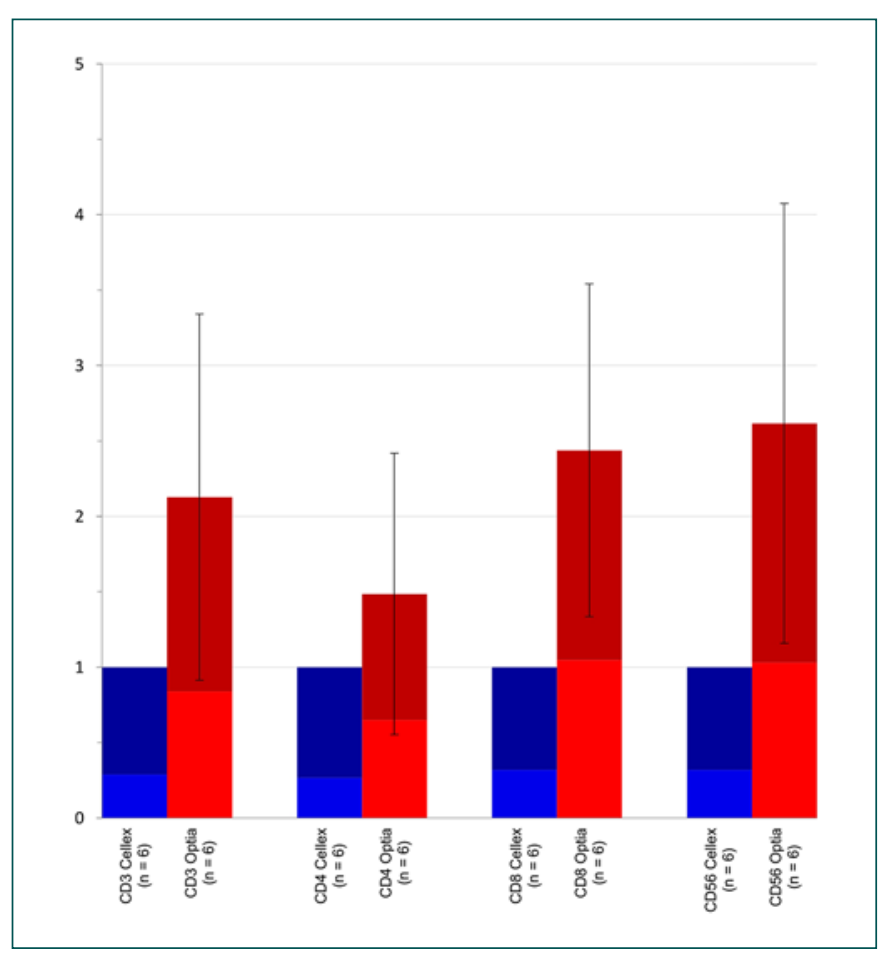

Fig. 3. Average relative apoptotic dose per patient after psoralen/ UVA and $24 \mathrm{~h}$. The dosage of each cell type has been stratified per patient; thus, the yield of the inline system (Cellex) is displayed with the value " $1 . "$ The variation represents the variation of the averaged values of each patient. Inline: blue; offline: red. The lighter colors represent the early, the darker colors the late apoptotic cells. apoptotic MNCs is the concentration of the respective "target" cells in the PB and, thus, the yield of cells during apheresis (data not shown). We were able to collect constantly and significantly more MNCs with the offline system Optia/MacoGenic in comparison to the inline Cellex system $(p<0.001)$. This difference has its origin, on the one hand, in the already established offline procedure in our department with and endpoint of $120 \mathrm{~mL}$ of apheresis product, which resulted in a higher processed blood volume (up to 4 -fold) in comparison to the inline procedure. On the other hand, the inline procedure followed recommendations released by the manufacturer with a fixed processed blood volume of $1,500 \mathrm{~mL}$. The upper limit of the processed volume is restricted to $2,000 \mathrm{~mL}$. The inline system collected more granulocytes, as also shown by other authors $[23,24]$. Recent findings indicate a promoting role of neutrophils at GvHD onset [25]; however, there is a lack of data on whether apoptotic neutrophils might have any effect in this regard. Although apoptosis is an ongoing process, the time point $24 \mathrm{~h}$ after irradiation treatment provides the largest increase in apoptosis [26] and was therefore used as a representative marker of apoptosis. In general, apoptosis levels were consistent with findings published by other groups [27]. Apoptosis induction was significantly higher in the inline system $(p<0.001)$, which also had a higher "background" apoptosis of untreated cells after $24 \mathrm{~h}$ compared to the offline 
procedure. The observed apoptosis level of untreated cells was higher than published elsewhere $[26,28]$. The underlying effect for this slight difference in apoptosis is unclear and has not been further investigated; one explanation could be the higher number of granulocytes, which were co-cultured during the 24 -h period.

The increased amount of MNCs collected with the offline method by far outweighed the lower apoptosis $(p<$ $0.001)$, resulting in a more than 2 -fold higher dose of apoptotic cells for the recipient. In that regard, the offline system clearly outperforms the inline system. However, no significant correlation between apoptotic cell numbers reinfused and clinical response has been reported so far.

An unexpected observation is the difference in CD4+ and CD8+ apoptotic cell levels that can be seen both in inline and offline treatment and which is highly significant $(p<0.001)$, contradicting a report by another group [26].

The collection volume of the offline system was kept at $120 \mathrm{~mL}$ because of the already established procedure. With a continuous collection system, this volume can be adjusted if indicated. The inline system, however, cannot regulate the apheresis procedure based on the product volume and features a fixed volume of processed blood by the manufacturer.

The apheresis procedure of the offline system requires a constant extracorporeal volume $(290 \mathrm{~mL})$, while in the inline system, the extracorporeal volume correlates indirectly with the HCT. Below an HCT of $39 \%$, the inline system results in an extracorporeal volume $>290 \mathrm{~mL}$. In consequence, some patients with a low HCT and body weight, who can undergo apheresis in the offline system, require a transfusion of at least 1 red blood cell unit before starting the inline apheresis procedure according to the manufacturer's instructions. Patients monitored in this paper did not require transfusion before treatment, but in other cases, treatment had to be delayed because of low HCT. However, patient-specific information (weight, HCT) itself is utilized only by the Optia system, which prevents an excessive infusion rate of anticoagulant. This is not controlled in the Cellex system. Handling of 8-MOP incubation and irradiation was more comfortable with the inline system. In the inline system, only one step, the addition of 8-MOP, is required. The offline system requires labelling of the irradiation bag, addition of a saline solution and 8-MOP, incubation, data entry at the irradiation device, irradiation, and retransfusion.

Time required per patient from start of apheresis to end of retransfusion with the inline system was $80-100$ min, while the offline system required about $3 \mathrm{~h}$ in our setup. Additionally, the inline device is limited to ECP, while the offline device can be utilized in a whole spectrum of apheresis procedures.

\section{Conclusion}

Based on our findings, there is no clear-cut recommendation for one system or the other. In any case, the documented and published clinical efficacy of each system is a prerequisite for using it for treatment. If patients have low MNC PB counts, the offline Optia/MacoGenic combination outperforms the inline Cellex system. Still, no significant correlation between apoptotic cell numbers reinfused and clinical response has been reported so far. The offline procedure is preferable if ECP requires a high number of lymphocytes/MNCs/kg body weight treated [22] or if additional apheresis procedures are part of the routine services of an institution. With close to normal peripheral MNC counts, the inline system has its benefits. If sufficient cells can be collected and time is relevant, the inline system will be preferred.

\section{Acknowledgement}

The authors thank the team of the quality control department for their diligent and extraordinary support for this project, namely Claudia Url, Alexandra Czeloth, and Eva Krasser.

\section{Statement of Ethics}

The study protocol was part of the established extended quality control of photopheresis products and did not require an ethics approval.

\section{Disclosure Statement}

The authors declare no competing financial interests.

\section{Funding Sources}

The study protocol was part of the established extended quality control of photopheresis products and funded through the routine budget of the department.

\section{Author Contributions}

W.H., S.S., A.G.-S., H.G., and P.S. provided substantial contributions to study conception and design; provided substantial contributions to acquisitions of data; provided substantial contributions to analysis and interpretation of data; drafted the article or critically revised it for important intellectual content; and provided final approval of the article to be published. 


\section{References}

1 Schwartz J, Padmanabhan A, Aqui N, Balogun RA, Connelly-Smith L, Delaney M, et al. Guidelines on the Use of Therapeutic Apheresis in Clinical Practice-Evidence-Based Approach from the Writing Committee of the American Society for Apheresis: The Seventh Special Issue. J Clin Apher. 2016 Jun;31(3): 149-62.

2 Knobler R, Barr ML, Couriel DR, Ferrara JL, photopheresis: past, present, and future. J Am Acad Dermatol. 2009 Oct;61(4):652-65.

3 Wolff D, Gerbitz A, Ayuk F, Kiani A, Hildebrandt GC, Vogelsang GB, et al. Consensus conference on clinical practice in chronic graft-versus-host disease (GVHD): first-line and topical treatment of chronic GVHD. Biol Blood Marrow Transplant. 2010 Dec;16(12): 1611-28.

4 Wolff D, Schleuning M, von Harsdorf S, Bacher U, Gerbitz A, Stadler M, et al. Consensus Conference on Clinical Practice in Chronic GVHD: Second-Line Treatment of Chronic Graft-versus-Host Disease. Biol Blood Marrow Transplant. 2011 Jan;17(1):1-17.

5 Hautmann AH, Wolff D, Hahn J, Edinger M, Schirmer N, Ammer J, et al. Extracorporeal photopheresis in 62 patients with acute and chronic GVHD: results of treatment with the COBE Spectra System. Bone Marrow Transplant. 2013 Mar;48(3):439-45.

6 Alfred A, Taylor PC, Dignan F, El-Ghariani K, Griffin J, Gennery AR, et al. The role of extracorporeal photopheresis in the management of cutaneous T-cell lymphoma, graftversus-host disease and organ transplant rejection: a consensus statement update from the UK Photopheresis Society. Br J Haematol. 2017 Apr;177(2):287-310.

7 Greinix HT, Volc-Platzer B, Rabitsch W, Gmeinhart B, Guevara-Pineda C, Kalhs P, et al. Successful use of extracorporeal photochemotherapy in the treatment of severe acute and chronic graft-versus-host disease. Blood. 1998 Nov;92(9):3098-104.

8 Flowers ME, Apperley JF, van Besien K, Elmaagacli A, Grigg A, Reddy V, et al. A multicenter prospective phase 2 randomized study of extracorporeal photopheresis for treatment of chronic graft-versus-host disease. Blood. 2008 Oct;112(7):2667-74.

9 Greinix HT, Knobler RM, Worel N, Schneieffect of intensified extracorporeal photochemotherapy on long-term survival in patients with severe acute graft-versus-host disease. Haematologica. 2006 Mar;91(3):405-8. French LE, Jaksch P, et al. Extracorporeal der B, Schneeberger A, Hoecker P, et al. The

10 Greinix HT, van Besien K, Elmaagacli AH, Hillen U, Grigg A, Knobler R, et al. Progressive improvement in cutaneous and extracutaneous chronic graft-versus-host disease after a 24-week course of extracorporeal photopheresis - results of a crossover randomized study. Biol Blood Marrow Transplant. 2011 Dec;17(12):1775-82.

11 Greinix HT, Volc-Platzer B, Kalhs P, Fischer G, Rosenmayr A, Keil F, et al. Extracorporeal photochemotherapy in the treatment of severe steroid-refractory acute graft-versushost disease: a pilot study. Blood. $2000 \mathrm{Oct}$; 96(7):2426-31

12 Greinix HT, Worel N, Just U, Knobler R. Extracorporeal photopheresis in acute and chronic graft-versus-host disease. Transfus Apher Sci. 2014 Jun;50(3):349-57.

13 Knobler R, Berlin G, Calzavara-Pinton P, Greinix H, Jaksch P, Laroche L, et al. Guidelines on the use of extracorporeal photopheresis. J Eur Acad Dermatol Venereol. 2014 Jan;28 Suppl 1:1-37.

14 Gasparro FP, Dall'Amico R, Goldminz D, Simmons E, Weingold D. Molecular aspects of extracorporeal photochemotherapy. Yale J Biol Med. 1989 Nov-Dec;62(6):579-93.

15 Wollowitz S. Fundamentals of the psoralenbased Helinx technology for inactivation of infectious pathogens and leukocytes in platelets and plasma. Semin Hematol. 2001 Oct; 38(4 Suppl 11):4-11.

16 Szczepiorkowski ZM, Burnett CA, Dumont LJ, Abhyankar SH. Apheresis buffy coat collection without photoactivation has no effect on apoptosis, cell proliferation, and total viability of mononuclear cells collected using photopheresis systems. Transfusion. 2018 Apr;58(4):943-50.

17 Dunbar NM, Raval JS, Johnson A, Abikoff CM, Adamski J, Cooling LL, et al. Extracorporeal photopheresis practice patterns: an international survey by the ASFA ECP subcommittee. J Clin Apher. 2017 Aug;32(4):215-23.

18 Iniesta $\mathrm{P}$, Revilla N, Chen-Liang TH, Hurtado AM, Vicente V, Heras I, et al. An early increase of CD56bright natural killer subset as dominant effect and predictor of response to extracorporeal photopheresis for graft-versus-host disease. Transfusion. 2018 Dec; 58(12):2924-32
19 Coppard C, Hannani D, Humbert M, Gauthier V, Plumas J, Merlin E, et al. In vitro PUVA treatment triggers calreticulin exposition and HMGB1 release by dying $\mathrm{T}$ lymphocytes in GVHD: new insights in extracorporeal photopheresis. J Clin Apher. 2019 Aug;34(4): 450-60.

20 Kuzmina Z, Greinix HT, Knobler R, Worel N, Kouba M, Weigl R, et al. Proportions of immature CD19+CD21- B lymphocytes predict the response to extracorporeal photopheresis in patients with chronic graft-versus-host disease. Blood. 2009 Jul;114(3):744-6.

21 Perseghin P, Galimberti S, Balduzzi A, Bonanomi S, Baldini V, Rovelli A, et al. Extracorporeal photochemotherapy for the treatment of chronic graft-versus-host disease: trend for a possible cell dose-related effect? Ther Apher Dial. 2007 Apr;11(2):85-93.

22 Worel N, Lehner E, Führer H, Kalhs P, Rabitsch W, Mitterbauer M, et al. Extracorporeal photopheresis as second-line therapy for patients with acute graft-versus-host disease: does the number of cells treated matter? Transfusion. 2018 Apr;58(4):1045-53.

23 Brosig A, Hähnel V, Orsó E, Wolff D, Holler E, Ahrens N. Technical comparison of four different extracorporeal photopheresis systems. Transfusion. 2016 Oct;56(10):2510-9.

24 Bueno JL, Alonso R, Gonzalez-Santillana C, Naya D, Romera I, Alarcón A, et al. A paired trial comparing mononuclear cell collection in two machines for further inactivation through an inline or offline extracorporeal photopheresis procedure. Transfusion. 2019 Jan;59(1):340-6.

25 Hülsdünker J, Ottmüller KJ, Neeff HP, Koyama M, Gao Z, Thomas OS, et al. Neutrophils provide cellular communication between ileum and mesenteric lymph nodes at graft-versus-host disease onset. Blood. 2018 Apr; 131(16):1858-69.

26 Budde H, Berntsch U, Riggert J, Legler TJ. In vitro effects of different 8-methoxypsoralen treatment protocols for extracorporeal photopheresis on mononuclear cells. Cent Eur J Immunol. 2017;42(1):1-9.

27 Taverna F, Coluccia P, Arienti F, Birolini A, Terranova L, Mazzocchi A, et al. Biological quality control for extracorporeal photochemotherapy: assessing mononuclear cell apoptosis levels in ECP bags of chronic GvHD patients. J Clin Apher. 2015 Jun;30(3):16270 .

28 Whittle RM, Taylor PC. Mechanism of Action of ECP. In: Greinix H, editor. Extracorporeal Photopheresis. Göttingen: De Gruyter; 2012. pp. 65-81.
Helmberg/Sipurzynski/Groselje-Strehle/ Greinix/Schlenke 